\title{
Groundwater Monitoring Network Design Using GIS and Multicriteria Analysis
}

\section{Juan M. Esquivel, Guillermo P. Morales \& María V. Esteller}

Water Resources Management

An International Journal - Published for the European Water Resources Association (EWRA)

ISSN 0920-4741

Volume 29

Number 9

Water Resour Manage (2015)

29:3175-3194

DOI 10.1007/s11269-015-0989-8

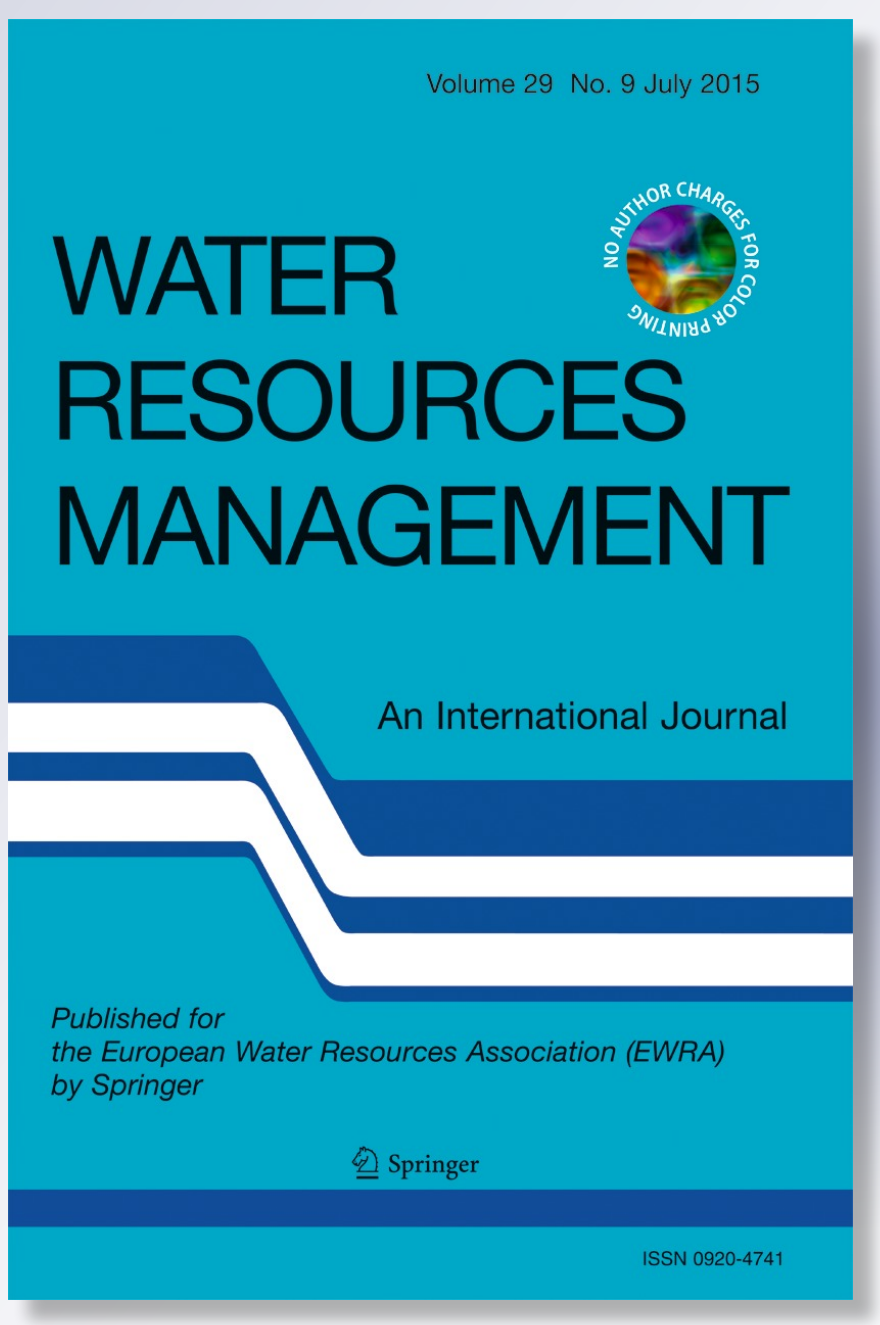

Springer 
Your article is protected by copyright and all rights are held exclusively by Springer Science +Business Media Dordrecht. This e-offprint is for personal use only and shall not be selfarchived in electronic repositories. If you wish to self-archive your article, please use the accepted manuscript version for posting on your own website. You may further deposit the accepted manuscript version in any repository, provided it is only made publicly available 12 months after official publication or later and provided acknowledgement is given to the original source of publication and a link is inserted to the published article on Springer's website. The link must be accompanied by the following text: "The final publication is available at link.springer.com". 


\title{
Groundwater Monitoring Network Design Using GIS and Multicriteria Analysis
}

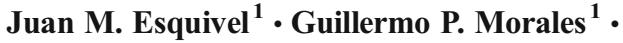 \\ María V. Esteller ${ }^{1}$
}

Received: 20 June 2014 / Accepted: 24 March 2015 /

Published online: 13 April 2015

(C) Springer Science+Business Media Dordrecht 2015

\begin{abstract}
The objective of this investigation was to use multicriteria analysis to analyze and model the main criteria that influence the optimal design of a network to monitor groundwater levels. The multicriteria analysis was performed using a GIS (IDRISI Selva). The Toluca Valley aquifer (Mexico) was chosen as the case study. The definition and importance of the criteria (factors and constraints) that influence the design of the monitoring network were based on available information and consultations with experts in the topic. The factors considered were: rate of decline in groundwater levels, decline in groundwater levels, rise in groundwater levels, cracks, vertical hydraulic gradient, and density of wells. The Analytical Hierarchy Process (AHP) was used to weight the factors, resulting in a consistency ratio of 0.08 . The weighted linear combination (WLC) method was then applied which resulted in a map identifying the locations of the priority areas to be monitored. The results show that $1.0 \%$ of the study region corresponds to very high priority monitoring areas, $1.8 \%$ to high priority areas, another $1.8 \%$ to medium priority, $4.4 \%$ to low priority and $91 \%$ to very low priority monitoring areas. The proposed method can be used by government and public and private organizations to determine monitoring strategies that support water resources management.
\end{abstract}

Keywords GIS · Analytical hierarchy process · Groundwater monitoring network

\section{Introduction}

Groundwater is a vital resource for the reliable and affordable supply of water for human use in urban and rural areas. According to UNESCO (2009), groundwater systems supply $48.23 \%$ of drinking water worldwide. Today, half of the megalopolises in the world and hundreds of large

María V. Esteller

mvestellera@uaemex.mx

1 Centro Interamericano de Recursos del Agua (CIRA) Facultad de Ingeniería, Universidad Autónoma del Estado de México, Cerro Coatepec S/N Ciudad Universitaria, 50130 Toluca, Estado de México, Mexico 
cities on every continent depend on groundwater. It is therefore a strategic resource and, thus, current and future calculations of the availability of groundwater are needed at all times to adequately plan, develop and manage water resources. Considering these circumstances, a groundwater monitoring program can provide the data required to make decisions related to the process to manage groundwater resources (Baalousha 2010). Such a monitoring program could also contribute to protecting groundwater since it would make it possible to evaluate pollution processes and problems of overexploitation of aquifers.

Tuinhof et al. (2002) indicate that a monitoring network is normally composed of a set of observation wells coupled with a determined number of extraction wells. In addition, a groundwater monitoring program includes a quantity network (groundwater level and recharge rates) as well as a quality network (analysis of physical-chemical variables). These networks must be optimized according to current and future needs as well as available economic resources.

Their design, implementation and optimization should take into account factors such as: geology, hydrodynamic characteristics of the aquifer, pollution points, vulnerability of the aquifer, location of wells, pumping regimes for wells, accessibility of monitoring points, operating and maintenance conditions, frequency of monitoring as well as financial costs (Preziosi et al. 2013; Mogheir et al. 2009; Díaz-Viera 2008; Molerio et al. 2002). It should also be noted that many of these criteria are dynamic (change over time) and, therefore, the functioning of monitoring networks should be optimized every times.

Since it may be complicated to include information about these diverse criteria in the optimal design of monitoring networks, tools such as geographic information systems (GIS) can be useful and help to facilitate the evaluation process. They can also serve to implement a multicriteria analysis (Uddameri and Andruss 2013; Eastman 2012; Cano-Casas and EscobarMartínez 2011; Weng 2005).

A multicriteria analysis (MCA) is a method used to evaluate several criteria defined for a specific objective, whose results enable making decisions (Saaty 1990). The objective of this method is to combine information from several criteria to create a single evaluation index. This multicriteria analysis has been applied to water resources management as a tool to support decision-making for cases in which several alternatives or possibilities exist (Van Gauwenberg et al. 2008; Hajkowicz and Collins 2007; Cai et al. 2004; Foukh 2001; Reitsma 1996). Thus, for case studies in which groundwater plays a main role, this method has been used to: select the criteria that need to be employed to designate suitable water catchment areas for fissured aquifers (Hanich et al. 2008); establish the most productive crop systems considering the costs of pumping groundwater, decreases in the groundwater level and pollution (Salazar et al. 2005); determine the best option for building a road given the need to protect groundwater (Eliasson et al. 2003); evaluate water management strategies for a watershed (Srdjevic et al. 2002); calculate the present and future need for water for human consumption (Rao 2005); support decision-making in order to satisfy new water demands at the local level (Cabrera et al. 2011); and evaluate the factors that make it possible to develop a potential water demand map (Panagopoulos et al. 2012); among others.

The multicriteria analysis includes different methods, such as: fuzzy set analysis, compromise programming (CP), analytical hierarchy process (AHP), ELECTRE I, II, III, IV and TRI, PROMETHEE I, II, V, multi-attribute utility theory (MAUT), multicriterion Q-analysis (MCQA, I, II and III), EXPROM, MACBETH, weighted summation and TOPSIS, among others (Hajkowicz and Collins 2007). AHP stands out among these methods as one of the most important techniques in multicriteria analysis (Marinoni 2004). It is one of the most commonly used methods in water resources management since it enables classifying the diverse criteria 
considered and weighting them based on their importance. Developed by Saaty (1990), AHP is a mathematical tool used to construct a hierarchical model that represents the problem to be studied by initially proposing criteria and alternatives, later deducing which of those are the best alternatives and making a decision.

The methods used to design monitoring networks are classified as (ASCE 2003): i) those based on rules in which the personal experience of a hydrogeological expert is combined with statistical methods; ii) statistics that include statistical comparisons, detection of trends and geostatistical methods involving variance, semivariogram evaluation, the theory of regionalized variables, etc.; iii) probabilistic techniques that involve the application of methods such as the Kalman filter, the hierarchical method and probabilistic simulation methods; and iv) mathematical optimization methods. Some of these methods also include the use of mathematical flow and transport models. Examples of these different techniques can be found in Júnez-Ferreira and Herrera (2013); Dhar and Patil (2012); Briseño-Ruiz et al. (2011); Zhang et al. (2005) and $\mathrm{Wu}$ (2004). These methods, and particularly those that are statistical, probabilistic and involve optimization, have been proven to be effective even though they are limited by the need for in-depth knowledge (large amount of data) about the aquifer and staff with the necessary knowledge to implement them (ASCE 2003). References have not been found in the scientific literature review on the use of the AHP in the design of monitoring networks, and those that have been found, such as Preziosi et al. (2013), use GIS and methods (GRID+PDA) to define groundwater quality monitoring networks.

Given the need to have increasingly more in-depth knowledge about groundwater resources that is supported by information obtained from monitoring programs, as well as to have an easily implemented method to design networks, the objective of this investigation was to: i) identify the criteria that influence the design of a monitoring network and ii) based on a case study (Toluca Valley aquifer, Mexico) develop a method for the optimal design of groundwater networks to monitor groundwater levels, using GIS and multicriteria analysis.

\section{Study Area}

\subsection{Overall Characteristics of the Study Area}

The Toluca Valley aquifer (TVA) is located in central Mexico, in the upper course of the Lerma River. It covers a total area of $2,768 \mathrm{~km}^{2}$. Its boundaries are the Atlacomulco-Ixtlahuaca aquifer to the north, the Tenango mountains to the south, the Nevado de Toluca volcano to the southwest (4 $680 \mathrm{msnm}$ ), the Corona mountains to the southeast and the Sierra de las Cruces and Monte Alto mountains to the east (Fig. 1).

In terms of the climate, most of the area is defined as sub-humid temperate C (w2) (w), while the northeastern portion of the region, which includes the Sierra de las Cruces and Monte Alto mountains, is semi-cold C (E) (w2) (w); the climate in the highest area, Nevado de Toluca, is very cold (E (T) H). Annual precipitation ranges between $1300 \mathrm{~mm}$ in the highest regions to $800 \mathrm{~mm}$ in the plains, most of which occurs between April and October. The mean annual temperature in the region is $14^{\circ} \mathrm{C}$, with a maximum of $17^{\circ} \mathrm{C}$ and a minimum of $0^{\circ} \mathrm{C}$.

The plain has an elevation of 2600 masl with an area of $1831 \mathrm{~km}^{2}$. Most of the human activity is carried out on this plain, which is also where the wells (roughly 1000) that exploit the aquifer are located. The Lerma River begins here, and although it is one of the largest rivers in this region its waters are not used because of its high pollutant load. Therefore, groundwater 


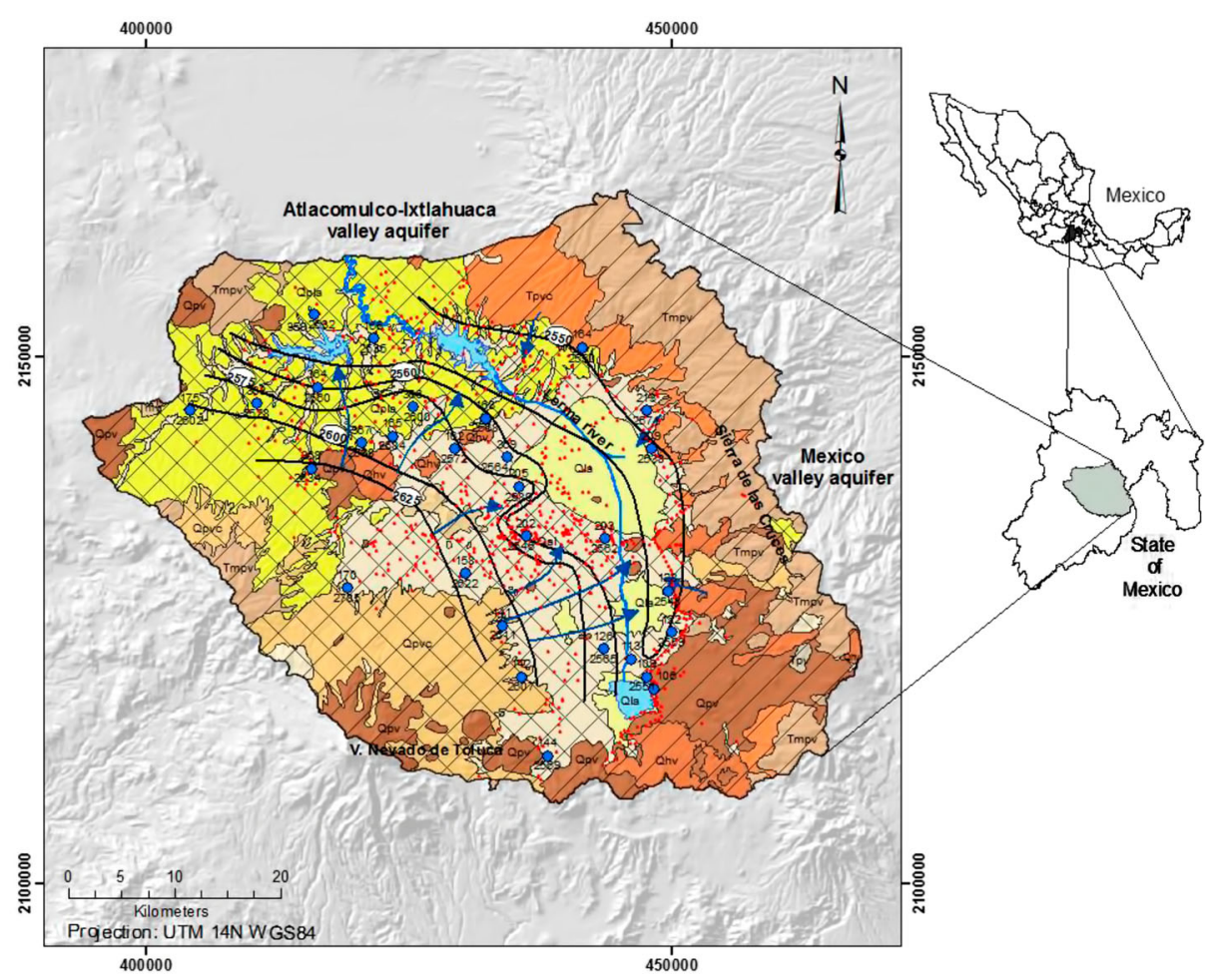

\section{Legend}
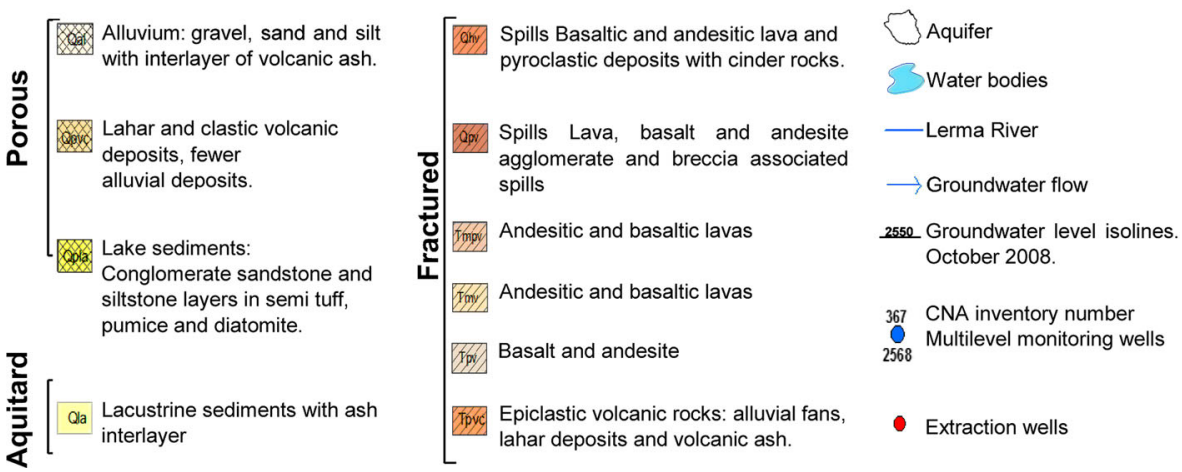

Fig. 1 Location of the Toluca Valley aquifer and main hydrogeological features

is the only source of water available to meet the needs of the area. In terms of the importance of this aquifer, of the $435 \mathrm{hm}^{3}$ of water extracted yearly (CONAGUA 2009), $84.7 \%$ is used for public-urban uses to supply the 2, 187,955 inhabitants in the Valley of Toluca (INEGI 2010) and a portion of the inhabitants in Mexico City, with a flow of $6 \mathrm{~m}^{3} / \mathrm{s}\left(189 \mathrm{hm}^{3} /\right.$ year).

The study aquifer is located in Trans-Mexican Neovolcanic Belt which experiences significant volcanic activity. The ages of the rock outcroppings in this region range from the Middle Tertiary (26 million years) to recent years and can be classified by 
three broad groups (UNAM 1994): 1) volcanic rocks located in the high regions, primarily consisting of basalts and andesite (geological units Qhv, Qpv, Qpvc, Tmpv, Tmv, Tpv) (Fig. 1); 2) pyroclastic material found bordering the mountains, including tuffs, agglomerates, breccias, volcanic ash and piedmont deposits (geological units Qpvc and Tpvc); and 3) materials from disintegration and erosion of the former two groups, mainly composed of sand, gravel, clay, silt and lacustrine deposits (geological units Qal, Qla and Qpla), which protrude out from the plains.

The basalts and andesites are found in large lava flows expulsed from fissures or from the numerous volcanoes located mainly in the southern portion of the aquifer. These rocks are generally very porous and permeable because of their numerous fractures and intercalations with layers of scoriaceous material, as occurs in the southern outcropping. These outcroppings are highly significant due to their large area and because they are considered an important aquifer recharge zone. Outcroppings of andesite and dacite rocks make up the core of the main mountain ranges - Sierra de las Cruces and Nevado de Toluca (CONAGUA-GTZ 2008).

Based on these characteristics, this system can be said to be made up of several superimposed aquifers constituting a multi-layer aquifer, while due to the existence of a certain amount of hydraulic continuity it can be considered to be a single flow system, although significantly different potentiometric head exist (Ariel Consultores 1996). Nevertheless, in general, two types of aquifer units can be distinguished: one with a porous medium composed of unconsolidated clastic fill deposits and another with volcanic rocks affected by tectonism with secondary permeability resulting from fracturing (Ariel Consultores 1996; CONAGUA-Desarrollo y Sistemas, S.A 2005; CONAGUA-GTZ 2008; CONAGUA 2009).

The porous aquifer has three main groundwater flows: one from infiltrations from the Nevado de Toluca with southwest-northeast flow, a second from the Nevado de Toluca flowing north to Ixtlahuaca and a third from Sierra de las Cruces flowing in a westerly direction (Fig. 1).

The Toluca Valley aquifer had remained unchanged until the early 1940s. In the 1950s, the Lerma System wells were drilled to supply drinking water to Mexico City. Later, the extraction of groundwater increased substantially over the years with the urban, agricultural and industrial growth that has characterized the region (Table 1). As a result, national water authorities consider this aquifer to be overexploited (CONAGUA 2009), causing significant negative effects in the study area, such as: decline in the groundwater level (at an average rate of $1.5 \mathrm{~m} /$ year), subsidence, cracks in the earth, drying up of surface water bodies, decreased flow in springs and changes in the quality of groundwater (Martín del Campo et al. 2014; Esteller et al. 2011; Calderhead et al. 2011; CONAGUA-GTZ 2008; Esteller and Diaz 2002).

\subsection{Monitoring Networks in the Toluca Valley Aquifer}

Currently, the TVA has two monitoring networks to evaluate impacts on the aquifer - a groundwater level network and a quality network. The groundwater level network (quantity network) was installed between 1968 and 1970 without any specific design criteria, considering only the most homogenous spatial distribution of observations points possible. The network consists of multilevel monitoring wells and data loggers. A multilevel monitoring well (Fig. 2) is a well in which a certain number of piezometers are installed at different depths (between 10 and $150 \mathrm{~m}$ ) and a data logger is a device that automatically measures groundwater levels in a well. 
Table 1 Water balance of the Toluca Valley Aquifer (Values in millions of $\mathrm{m}^{3}$ annual)

\begin{tabular}{|c|c|c|c|c|c|c|c|}
\hline & $\begin{array}{l}1970 \\
\text { (CNA, } \\
2002)\end{array}$ & $\begin{array}{l}1992 \\
\text { (Lesser y } \\
\text { Asoc. } \\
\text { 1992) }\end{array}$ & $\begin{array}{l}1993 \\
\text { (CCRECL, } \\
1993)\end{array}$ & $\begin{array}{l}1996 \text { (Ariel } \\
\text { Consultores } \\
1996)\end{array}$ & $\begin{array}{l}2000 \\
\text { (CNA, } \\
2002)\end{array}$ & $\begin{array}{l}2004 \\
\text { (CNA- } \\
\text { GTZ, } \\
\text { 2004) }\end{array}$ & $\begin{array}{l}2009 \\
\text { (CONAGUA } \\
2009)\end{array}$ \\
\hline \multicolumn{8}{|l|}{ Inputs } \\
\hline $\begin{array}{l}\text { Groundwater inputs } \\
\text { (Nevado de Toluca) }\end{array}$ & & & 101 & 94.5 & 94.6 & 130 & \\
\hline $\begin{array}{l}\text { Groundwater inputs } \\
\text { (Sierra de las Cruces) }\end{array}$ & & & 198 & 63.0 & 63.1 & 200 & \\
\hline Total inputs & & 299 & 299 & 157.5 & 157.7 & 330 & \\
\hline $\begin{array}{l}\text { Natural vertical } \\
\text { recharge }\end{array}$ & & 81 & 81 & 98.2 & 177.8 & 100 & \\
\hline $\begin{array}{l}\text { Natural recharge } \\
\text { induced }\end{array}$ & & & & 0.8 & 1.3 & & \\
\hline Sum & 342.1 & 380 & 380 & 256.5 & 336.8 & 430 & 336.8 \\
\hline \multicolumn{8}{|l|}{ Outputs } \\
\hline Groundwater outputs & 2.0 & 2 & 2 & 0.0 & 0.0 & 0 & \\
\hline Extraction & 353.9 & 327 & 383 & 327.4 & 422.4 & 460 & 435.6 \\
\hline Evapotranspiration & & 10 & & 14.7 & 0.0 & 0 & \\
\hline River discharge, spring & & & & & 53.6 & 0 & 53.6 \\
\hline Sum & 355.9 & 339 & 385 & 342.1 & 476.0 & 460 & 489.6 \\
\hline Change storage & -13.8 & 41 & -5 & -85.5 & -85.6 & -30 & -152.5 \\
\hline
\end{tabular}

Initially, during the 1970s measurements were taken as often as seven times per year. Later, in the 1990s they were taken four times, and finally, in 2008, just once per year (CONAGUA 2012).

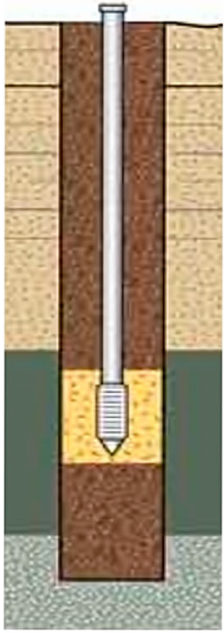

Piezometer
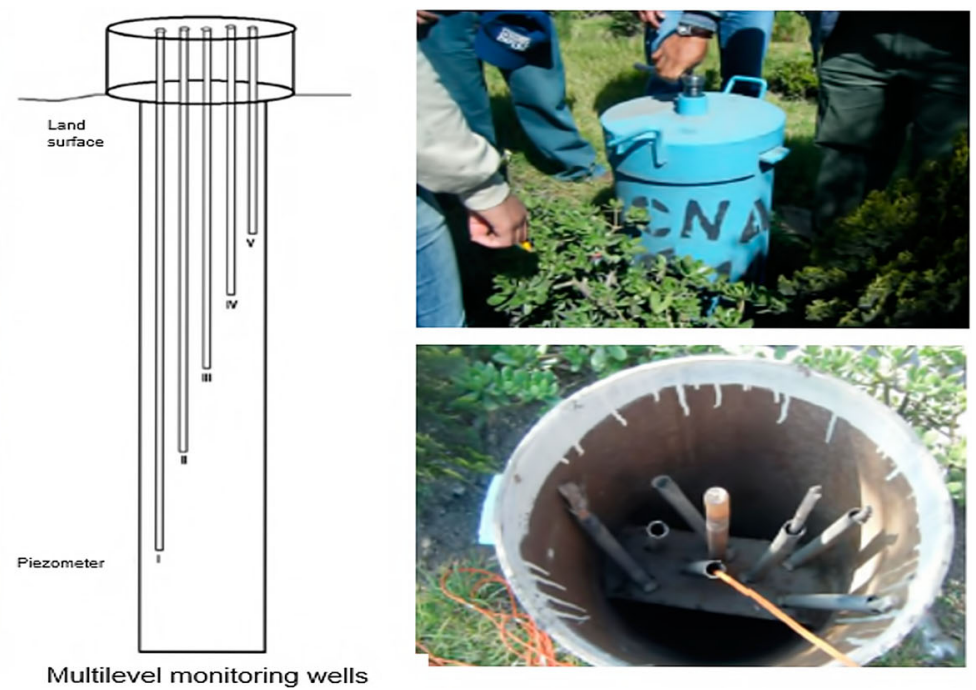

Fig. 2 Schematic of a multilevel monitoring wells and installation view 


\subsection{Evaluation of the Existing Groundwater Level Monitoring Network}

The groundwater level network has 77 monitoring points as of 2013, of which 62 are multilevel monitoring wells and 15 are data loggers (Fig. 3). As a first step in this investigation, the operating state was evaluated in situ, which showed blockages of some of the multipiezometers. The evaluation classified them as operating, partially operating (water level can be measured in only some of the piezometers) and not operating. Currently, 35 multilevel monitoring wells are operating, 25 are partially operating and 2 are not operating. In terms of the data loggers, 11 are working correctly and four are not functioning because of vandalism and a lack of maintenance.

\section{Materials and Methods}

\subsection{Identification and Selection of Criteria (factors and constraints)}

The proposed objective for the MCA was defined as "monitoring" and consisted of identifying and locating the priority monitoring areas in the groundwater level.

The first step involved selecting the criteria (factors and constraints) that influence the design of monitoring networks, which took into account the available information and consultation with experts. The experts consulted worked in the Inter-American Water

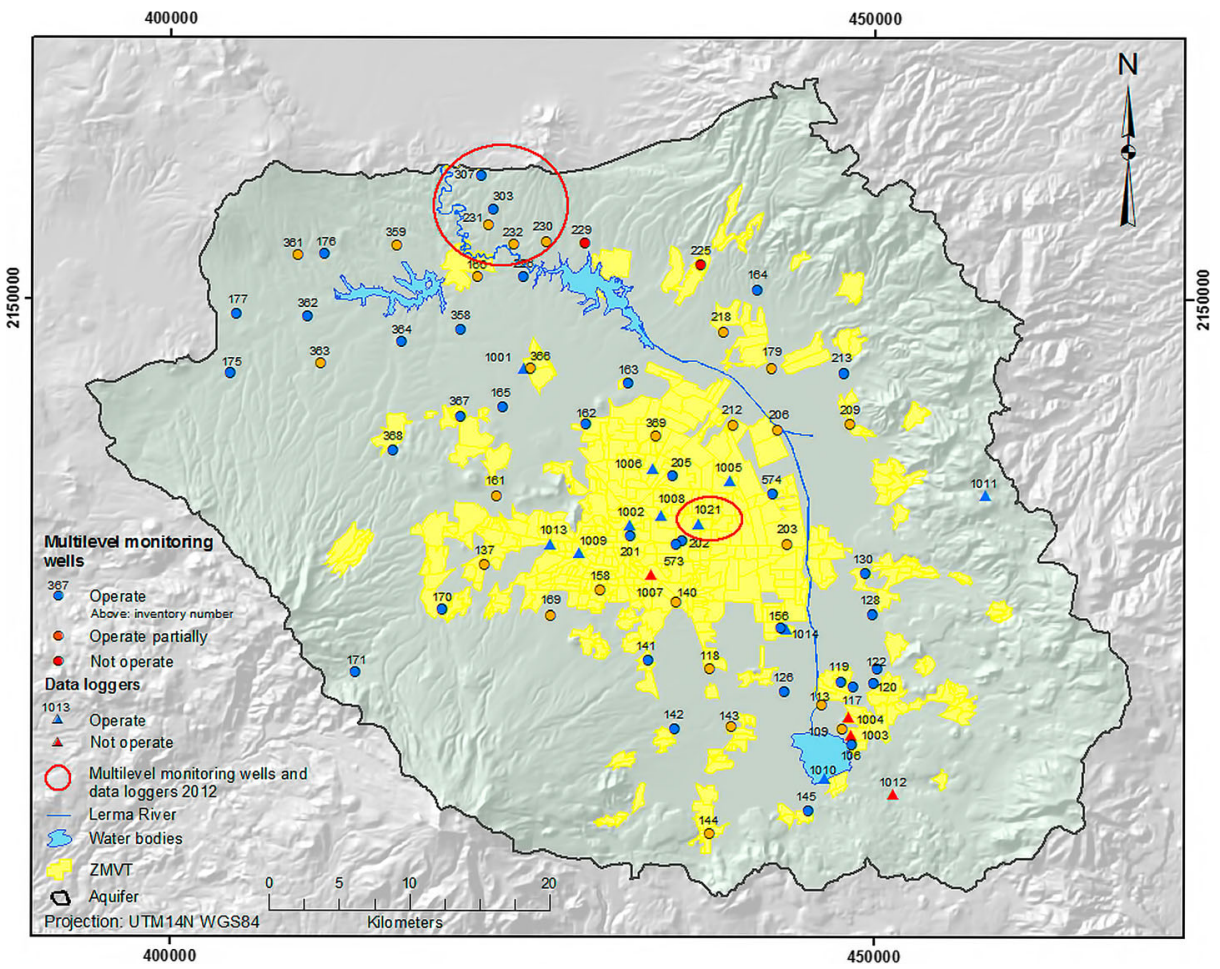

Fig. 3 Location and classification of monitoring points that make up the quantity network 
Resources Center (Centro Interamericano de Recursos del Agua; CIRA, Spanish acronym) at the Autonomous University of the State of Mexico (UAEM, Spanish acronym) and the National Autonomous University of Mexico (UNAM, Spanish acronym), as well as government agencies such as the National Water Commission (CONAGUA, Spanish acronym), the Mexican Institute of Water Technology (IMTA, Spanish acronym) the National Institute of Statistics Geography and Informatics (INEGI, Spanish acronym) and the State of Mexico Institute for Mining and Geological Studies (IFOMEGEM; Spanish acronym) - all entities involved in issues pertaining to groundwater.

The personal experience of experts who have conducted other studies and the availability of information made it possible to define six factors and two constraints as the most influential criteria in the future process for the optimal design of the groundwater level monitoring network (Table 2). These are:

\section{i Decline in Groundwater Levels}

This was calculated based on the depths of the groundwater levels registered on two different years — an initial depth (1968) and a final depth (2011). The depth of the groundwater level during the initial year $(\mathrm{Li})$ was subtracted from the level during the final year (Lf). The data included corresponded to the deepest piezometer (installed 100 to $150 \mathrm{~m}$ deep) because it is the one that responds to the dynamics of the aquifer, since most of the exploitation wells are over $100 \mathrm{~m}$ deep (Martín del Campo et al. 2014).

The isolines of the groundwater levels were interpolated with decreases of 10, 20, 30, 40 and $50 \mathrm{~m}$ for the period 1968-2011. These intervals were chosen in order to simply obtain a suitable cartographic representation of the variability in areas with larger and smaller decreases (Fig. 4a).

This factor represents changes in the dynamics of the aquifer that occur mainly as a result of the intensive exploitation of the aquifer and enables defining drawdown cones extending for kilometers.

\section{ii Rise in Groundwater Levels}

Recovery of groundwater levels was observed in some piezometers, and therefore this factor was also considered (Fig. 4b). This also represents changes in the dynamics of the aquifer.

\section{iii Rate of Decline in Groundwater Levels for a Defined Period of Time}

This factor was chosen because areas with higher rates of decline are priority monitoring areas since the effect of overexploitation of the aquifer is more intensely reflected in

Table 2 Criteria selected for the design of monitoring network

\begin{tabular}{lll}
\hline Criterion & Classification & Information Source \\
\hline Decline in groundwater levels & Factor & Based on information from CONAGUA. \\
Rise in groundwater levels & Factor & Based on information from CONAGUA. \\
Rate of decline in groundwater levels & Factor & Based on information from CONAGUA. \\
Density of extraction wells & Factor & Based on information from CONAGUA. \\
Vertical hydraulic gradient & Factor & Expósito (2012) \\
Cracks & Factor & Paredes (2010) \\
Mountains and water bodies & Constraint & Considering the INEGI topographic map (1997). \\
Limit aquifer & Constraint & Based on the limit defined by CONAGUA (2009). \\
\hline
\end{tabular}



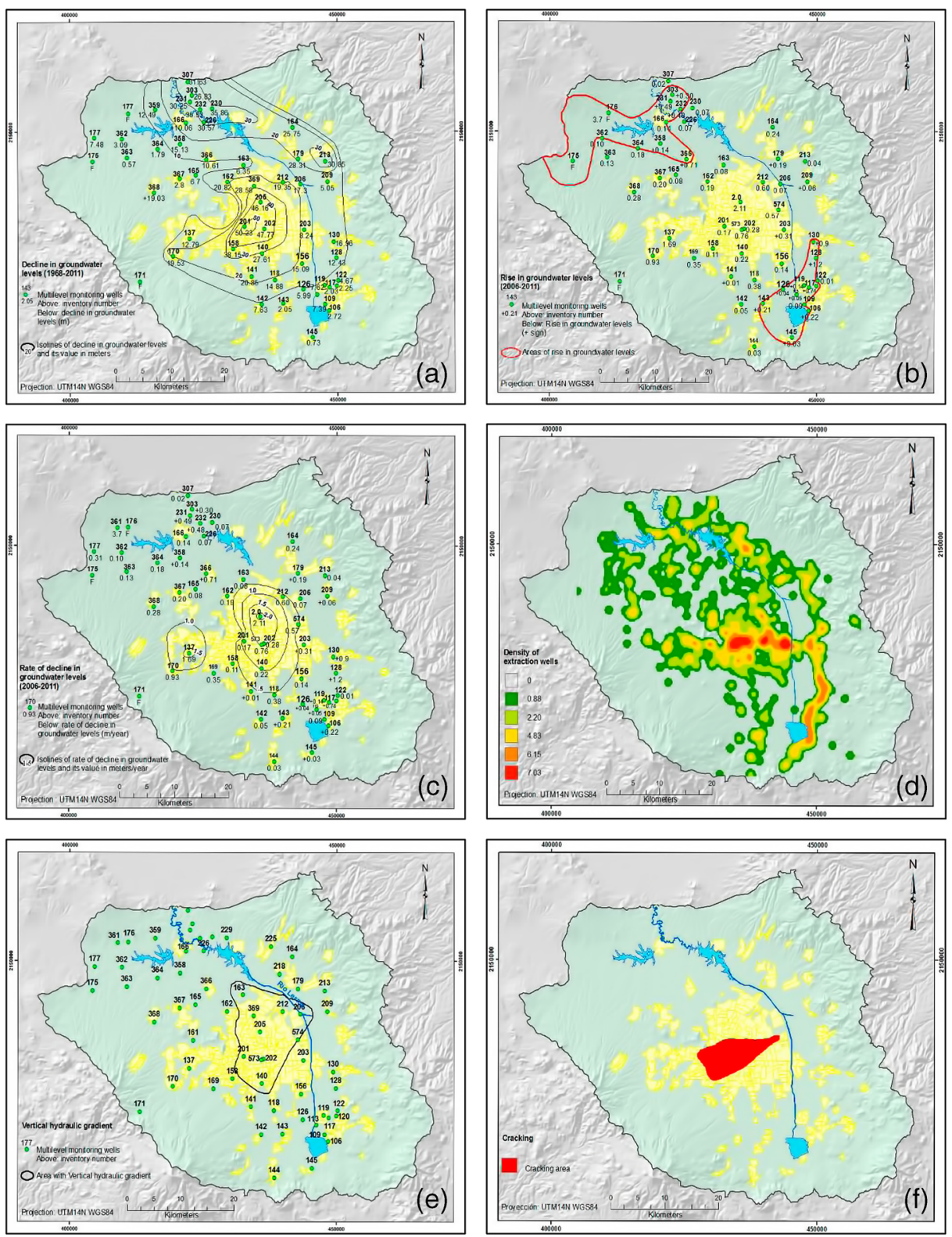

Fig. 4 Maps of the factors involved in the study. a decline in groundwater levels, $\mathbf{b}$ rise in groundwater levels, $\mathbf{c}$ rate of decline in groundwater levels, $\mathbf{d}$ density of extraction wells, e vertical hydraulic gradient y $\mathbf{f}$ cracking

these regions.

A cartographic map was generated with the values for the rate of decline, which were determined by dividing the value corresponding to a decrease in a piezometer by the number of years of the time period considered (2006-2011). The data represented the deepest piezometer.

A cartographic map of isolines for 0.5, 1.0, 1.5 and $2.0 \mathrm{~m} /$ year was generated (Fig. 4c). 


\section{iv Density of Extraction Wells}

This criterion is defined as the number of wells per unit area. This factor was chosen because of the need to monitor areas with a high density of wells since these areas can present synergetic phenomena and more intense exploitation.

The database of extraction wells developed by the IMTA (2003) was used to determine the density of wells, which is the number of wells per $\mathrm{km}^{2}$. The calculation was performed using ArcGis 10 software. The density obtained ranged from 0 to 7 wells $/ \mathrm{km}^{2}$ (Fig. 4d).

v Vertical Hydraulic Gradient

An area with vertical hydraulic gradient is one of the most important elements to identify the susceptibility of regions to pollutants passing from the land surface to the most productive portion of the aquifer (Cherry et al. 2004). It is also essential to understanding which areas are most intensely exploited and how the vertical gradient behaves in these areas.

The multilevel monitoring wells with downward vertical gradient (vertical flow from the surface to greater depths) were selected based on the measurements of groundwater levels from each of the piezometers installed at different depths (Expósito 2012).

A map was generated which identified the portions of the aquifer with a downward vertical gradient (Fig. 4e).

vi Cracks

While cracking of land can be caused by several factors (Orozco and Figueroa 1991), one of the main reasons is the intensive extraction of groundwater (Garduño et al. 2001). This geological phenomenon has accelerated in the TVA over recent decades, significantly damaging the urban infrastructure (streets, housing, drinking water networks, sewage and cable networks, etc.) due to cracking in the urban areas of the City of Toluca (Fig. 4f).

This factor can affect the polluting of groundwater since it can act as a preferential flow route for a pollutant (Martín del Campo et al. 2014; Mejía 2007; Bense et al. 2003).

\subsection{Standardization of Criterion Scores (Factors and Constraints)}

The factors considered had different scales and units (Table 3), such as the rate of decline in groundwater levels (m/year), decline in groundwater level $(\mathrm{m})$ and density of extraction wells (no. of wells $/ \mathrm{km}^{2}$ ). Therefore, these factors were standardized to obtain a common scale (byte 0 to 255) using the IDRISI-GIS fuzzy module. This standardizing was performed so that all the maps of the factors would be positively correlated with the suitability. These were standardized according to the following equation:

$$
X i=\frac{(R i-R \min )}{(R \max -R \min )} \cdot S R
$$

Where:

$\mathrm{Xi} \quad$ New value, standardized by pixel

$\mathrm{Ri} \quad$ Value of the factor, by pixel

Rmin Minimum value of the factor, by pixel

Rmax Maximum value of the factor, by pixel

SR Maximum threshold of the range to be standardized, in this case, 255 
The pertinence function (monotonically increasing function) also needed to be defined for each factor based on the theory of fuzzy groups, or fuzzy logic (Eastman 2012). Standardizing each of the maps of the factors required identifying the minimum and maximum values of the original scales (images included).

Later, a second classification was developed for factors having a value of "0" (byte scale), which was changed to 1 (rate of decline and decline in groundwater levels) since some presence of the factor in question (even if irrelevant) could not be discarded. Meanwhile, a " 0 " value for the density of wells remained " 0 " (representing the inexistence of wells).

The IDRISI-GIS fuzzy module was not applied to the vertical hydraulic gradient, increased groundwater levels and cracking. These factors were classified using a byte scale (1-255) since only their presence or absence was considered. The maximum value (255) was assigned to sectors where the existence of the factor was detected (if there was an increase in the groundwater level, if cracks were identified and if there was a downward vertical gradient) since these are areas that need monitoring points.

The Boolean method ( 0 and 1$)$ was applied to the constraints, where " 0 " represented the areas where monitoring was not possible and " 1 " represented areas where it was possible.

The maps generated of the rescaled factors are presented in Fig. 5.

\subsection{Weighting Process}

After selecting and standardizing the factors, the next step was to identify the weight of each factor. This consisted of assigning the value of the importance of one factor with respect to another in terms of the importance or influence it has in achieving the proposed objective (Eastman 2012).

Since the weights should not be assigned arbitrarily it is advisable to obtain the support of a panel of experts on groundwater monitoring. Therefore, surveys were administered to several experts with professional experience in the areas of hydrogeology and geographic information systems. Each of the experts compared the different factors, based on which a hierarchy was developed.

After defining the importance of each factor, the IDRISI-GIS Decision Wizard module was applied to obtain the weights of the factors. To this end, one of three methods had to be chosen:

a) Equal weights

b) Weights defined by the user

c) Analytical Hierarchy Process

The AHP method was selected for the present study and was applied using the IDRISI-GIS Weight module which automatically performs paired comparisons. The AHP was used to construct matrices based on these comparisons and elements of matricial algebra was applied to establish priorities between the factors on one level with respect to an element one level above it (Osorio and Orejuel 2008).

The process of paired comparisons was performed using a scale of 9 points corresponding to levels of importance: $1=$ equal, $3=$ moderate, $5=$ high, $7=$ very high and $9=$ extreme, while 2 , 4, 6 and 8 were used when the preference among the factors could not be clearly defined, in which case they were considered intermediate preference values (Saaty 1977).

A whole number was assigned in the matrix if the row factor was more important to the study's objective than the column factor, and if it was not more important a fraction was used. 


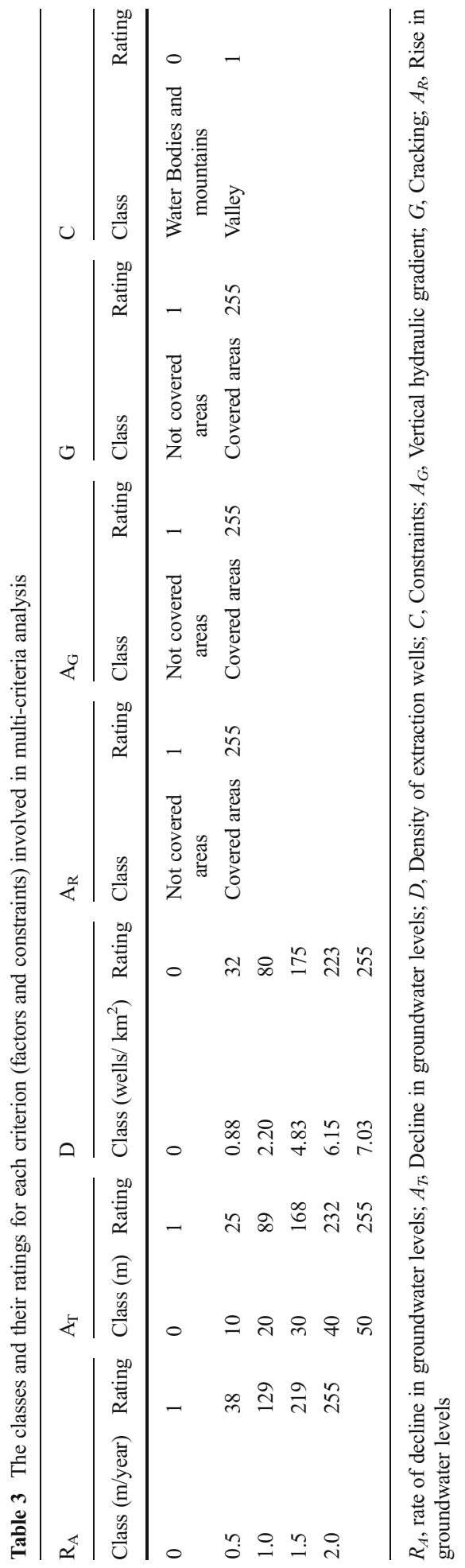



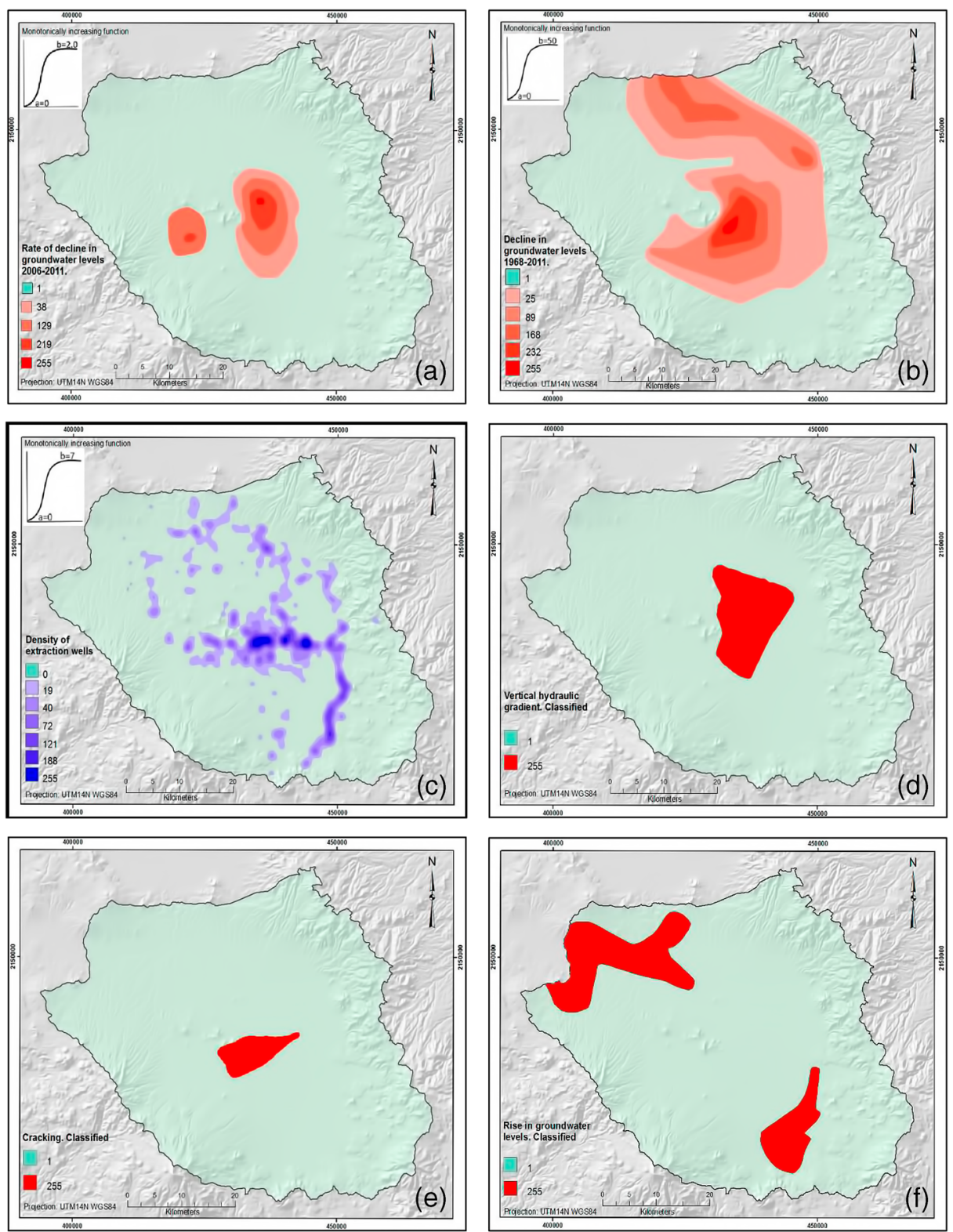

Fig. 5 Standardized maps of the factors involved in the study area. a rate of decline in groundwater levels, b decline in groundwater levels, $\mathbf{c}$ density of extraction wells, $\mathbf{d}$ vertical hydraulic gradient, $\mathbf{e}$ cracking and $\mathbf{f}$ rise in groundwater levels

The value assigned to each column to be compared must be a product of the survey of experts. After the comparison of factors was complete, the Weight module was run to calculate the weights of each factor, which are presented in a table called proper vector (Saaty 2006). The value of the weights, the weighting coefficients and the order of importance of each factor used is presented in Table 4. The order of importance of the factors was: 1) rate of decline, 2) 
decline in groundwater level, 3) density of extraction wells, 4) vertical hydraulic gradient, 5) cracks and 6) rise in groundwater level.

The consistency ratio "CR" was also calculated. According to Saaty (1990), when the CR is less than 0.1 , the weighting coefficients are acceptable. The consistency is defined as:

$$
C R=\frac{C I}{R I}
$$

Where:

RI Random index (1.24 for this investigation)

CI Consistency index

The consistency index is calculated as:

$$
C I=\frac{\lambda \max -n}{n-1}
$$

Where:

$$
\begin{array}{ll}
\lambda \max = & \sum \lambda \mathrm{i} . \text { Total } \mathrm{i} \\
\lambda & \text { Vector or weights per factor } \\
n & \text { Number of factors }
\end{array}
$$

The consistency ratio obtained for the present case study was acceptable, with a value of 0.08 .

After the relative weights of the factors were obtained, the next step was to take the aggregation all the criteria (factors and constraints) that had been created. An evaluation (or aggregation) step was performed to combine the information about the factors and constraints. The MCE module provides three logics to evaluate/ aggregation the multiple criteria: Boolean intersection, weighted linear combination (WLC) and ordered weighted average (OWA).

\subsection{Evaluation}

Finally, to apply the multi-criteria analysis, the weighted linear combination (WLC) method was chosen since it allows for more decision options than the Boolean method, which is one of the simplest ones, and also because it smoothes the hard decisions of the Boolean constraint and assumes medium risks (Eastman 2012).

Table 4 The weighting coefficient of every factor and their weights

\begin{tabular}{llllllll}
\hline & $\mathrm{R}_{\mathrm{A}}$ & $\mathrm{A}_{\mathrm{T}}$ & $\mathrm{D}$ & $\mathrm{A}_{\mathrm{G}}$ & $\mathrm{G}$ & $\mathrm{A}_{\mathrm{R}}$ & Weights \\
\hline $\mathrm{R}_{\mathrm{A}}$ & 1 & & & & & & 0.4575 \\
$\mathrm{~A}_{\mathrm{T}}$ & $1 / 3$ & 1 & & & & & 0.2632 \\
$\mathrm{D}$ & $1 / 5$ & $1 / 3$ & 1 & & & & 0.1406 \\
$\mathrm{~A}_{\mathrm{G}}$ & $1 / 7$ & $1 / 5$ & $1 / 3$ & 1 & & & 0.0740 \\
$\mathrm{G}$ & $1 / 7$ & $1 / 7$ & $1 / 5$ & $1 / 3$ & 1 & & 0.0412 \\
$\mathrm{~A}_{\mathrm{R}}$ & $1 / 9$ & $1 / 9$ & $1 / 7$ & $1 / 5$ & $1 / 3$ & 1 & 0.0235 \\
\hline
\end{tabular}

$R_{A}$, rate of decline in groundwater levels; $A_{T}$, Decline in groundwater levels; $D$, Density of extraction wells; $A_{G}$, Vertical hydraulic gradient; $G$, Cracking; $A_{R}$, Rise in groundwater levels 
The objective of the WLC method is to generate a map from the results of the multiplication of the factors by the weights (Fig. 5) and a second multiplication of those results by the constraint (Boolean maps 0 and 1). This method is an application of the map algebra technique which is based on a series of algebraic and logic operations applied to a group of raster data (Eastman 2012).

\section{Results}

The weighted linear combination is the method most commonly used to evaluate multiple criteria. This combination was performed based on the following mathematical formula (Marinoni 2004):

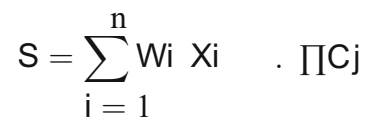

Where:

$$
\begin{array}{ll}
\mathrm{S} & \text { Suitability } \\
\mathrm{n} & \text { Number of factors } \\
\mathrm{Wi} & \text { Weight of factor } i \\
\mathrm{Xi} & \text { Value of factor } i \\
\mathrm{Cj} & \text { Criterion score of the constraint } j . \\
\Pi & \text { Product of the constraints (with } j=1 . . \mathrm{n} \text { ) }
\end{array}
$$

Finally, the map resulting from the multi-criteria analysis was obtained using a scale of 0 to 255 and was classified according to the categories that would provide the best definition of the priority areas to be monitored (Table 5): 1) very low, 2) low, 3) medium, 4) high and 5) very high monitoring priority (Fig. 6).

According to this categorization, $91 \%$ of the plain is a "very low" priority. The "low" priority areas are in the northern and western portions of the plain where the Toluca Valley aquifer is found, and covers $4.4 \%$ of the area. The "medium" priority corresponds to $1.8 \%$ of the area and is located primarily in the central portion of the study area. The "high" category covers part of the center of the aquifer (only $1.8 \%$ of the total). The area that is a "very high" priority corresponds to the City of Toluca metropolitan zone and covers a small portion $(1.0 \%)$ of the entire plain area. The factors having the most weight converge in this area (Table 4): higher rate of decline, greater decline, vertical hydraulic gradient, existence of cracks and higher density of extraction wells. Therefore, more efforts are needed to obtain an adequate

Table 5 Categories of multicriteria analysis

\begin{tabular}{ll}
\hline Byte Scale & Importance \\
\hline $1-45$ & Very low \\
$45-90$ & Low \\
$90-135$ & Medium \\
$135-180$ & High \\
$180-255$ & Very High \\
\hline
\end{tabular}




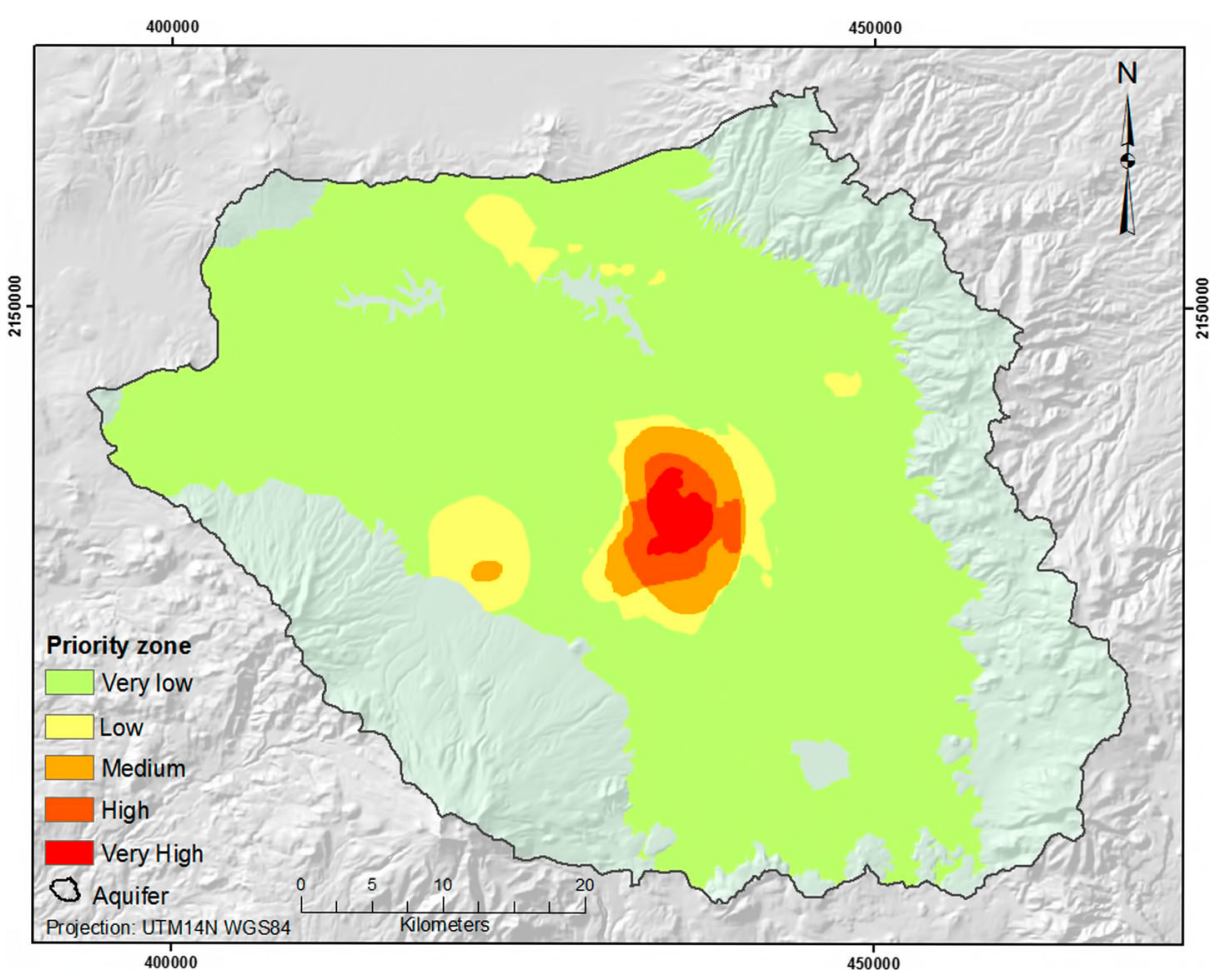

Fig. 6 Map of priority áreas for groundwater level monitoring

monitoring network in this region and thereby have more precise data regarding changes in the dynamics of the aquifer.

\section{Discussion}

As was mentioned, the AHP is a method to support decision-making, especially with regard to planning, since it enables the integration into a single analysis framework of different common criteria related to the objective of the investigation and based on the opinion of experts. It is used to assist decision-making processes by allowing for different points of view to be considered even when they may be contradictory.

Eight criteria (six factors and two constraints) were thereby available and selected which were considered most important to the design of the groundwater level monitoring network in the TVA. The factors were rescaled and the numerical classes were standardized using a byte scale ( 0 to 255$)$, while a Boolean scale ( 0 and 1$)$ was used for the constraints. The criteria used by this study are not the only ones that can be employed. A wide range of criteria (land subsidence, recharge, geomorphology, meteorological information, among others) can be included depending on the information available about a particular aquifer.

Weighted linear combination (WLC) was applied to obtain an aggregation of the factors, resulting in a map of priority monitoring areas classified according to five levels of importance (very high, high, medium, low and very low). In the present study, $2.8 \%$ of the plain area is 
considered to have a high and very high monitoring priority and thus urgently needs monitoring points. Therefore, new multilevel monitoring wells should be installed as soon as funds are available, while some of those in the existing exploitation wells could be used as an emergency measure (although their use has its limitations because those well are usually intensively exploited).

The final map was spatially related to the behavior of the criteria used in the investigation, demonstrating consistency with the proposed methodology. As is the case for other methods, the application of the AHP has its limitations since this analysis is usually based on lengthy and iterative processes that can require an important and long period of negotiation to reach consensus about the criteria to be considered and their weights. Nevertheless, it is a highly useful tool (Mei et al. 1989; Marinoni 2004) whose application has been demonstrated to be feasible in a large number of studies related to water resources (Hajkowicz and Collins 2007). In these studies, AHP was applied to define the order of importance of factors related to the research objectives and to assign weights to factors (which is usually the critical point in decision-making) based on the opinion of a group of experts on the subject.

This method could be applied to aquifers with very diverse characteristics, with the greatest limitation being the lack of reliable data needed to establish and validate the method. One recommendation would be to validate the method using the same criteria while applying another type of geostatistical method, as proposed by Júnez-Ferreira and Herrera (2013) or to perform a sensitivity analysis as described by Preziosi et al. (2013).

This entire process to define the monitoring network was implemented with the help of IDRISI GIS software. Since this software is more geared towards teaching and research, it presents limitations when used by government entities (which in Mexico are responsible for monitoring) and users associations. Nevertheless, the multi-criteria analysis can be applied with other commercial software (ArcGis 10, MPC 2.0, Criterium Decision Plus, etc.) that tend to be more available to the general public.

A next step in this work would be to determine the number of monitoring wells needed to install in these priority areas and the frequency of data measurements. To this end, methods such as those presented by Wu (2004) and Júnez-Ferreira and Herrera (2013) could be used. It is important to remember the cost/benefit analysis, which could be performed with the method proposed by Mogheir et al. (2009).

\section{Conclusions}

The optimal design of the monitoring network focused on the study of changes in groundwater levels. From a water management perspective, this should be considered an essential element in making decisions based on precise and quality information. With the help of a GIS, this investigation applied the AHP method to perform a multi-criteria analysis to optimize the groundwater level monitoring network in the Toluca Valley Aquifer (Mexico), since it is a simple and efficient tool for topics related to water resources.

The first step in the AHP was to select the criteria relevant to improving the spatial distribution of the monitoring points in the network. The factors selected for the groundwater level network were: rate of decline, decline in groundwater level, density of extraction wells, cracks, vertical hydraulic gradient and rise in groundwater levels. These were chosen because they were considered to be indicators that enable evaluating the degree of overexploitation of the aquifer and its impacts. 
The factors were standardized to a byte scale (0-255) in order to improve the display and calculation efficiency. The monotonically increasing sigmoidal function required two control points to minimize the range in the standardized values between control points, according to the objective.

The weighting of factors required the opinion of experts in groundwater and GIS, who also were familiar with the characteristics of the TVA and its problems. The relative weights were obtained quickly with the help of IDRISI GIS software and with an acceptable consistency rate (less than 0.1).

The evaluation of the factors was performed using weighted linear combination assuming medium risk for decision-making. The resulting map was reclassified into categories in order to locate the priority monitoring areas.

One of the advantages of the AHP is that it supports making decisions related to complex problems. The basis on which the criteria are selected and the scoring of the results are often simple and understandable, and are determined by a group of experts.

Acknowledgments This work was supported by a grant from the Universidad Autonoma del Estado de Mexico (Project 3318/2012CHT). The authors wish to thanks the personnel at the Comision Nacional de Agua (CONAGUA) and the CIRA researches for their comments and suggestions.

\section{References}

ASCE (2003) Long-term groundwater monitoring design. The state of the art American Society of Civil Engineers, EWRI, USA

Baalousha H (2010) Assessment of a groundwater quality monitoring network using vulnerability mapping and geostatistics: a case study from heretaunga plains, New Zealand. Agric Water Manag 97:240-246

Bense VF, Van Den Berg EH, Van Balen RT (2003) Deformation mechanisms and hydraulic properties of fault zones in unconsolidated sediments, the Netherlands. Hydrog J 11(3):319-332

Briseño-Ruiz JV, Herrera-Zamarrón GDS, Júnez-Ferreira HE (2011) Method for the optimal design of networks to monitor groundwater levels [Método para el diseño óptimo de redes de monitoreo de los niveles del agua subterránea]. Water Sci Technol 2(4):77-96

Cabrera E, Cobacho R, Estruch V, Aznar J (2011) Analytical hierarchical process (AHP) as a decision support tool in water resources management. J Water Supply Res Technol 60(6):343-351

Cai X, Lanson L, Michelen AM (2004) Group decision making in water recourses planning using multiple objective analysis. J Water Res Pl-ASCE 130(1):4-14

Calderhead AI, Therrien R, Rivera A, Martel R, Garfias J (2011) Simulating pumping- induced regional land subsidence with the use of InSAR and field data in the Toluca Valley, Mexico. Adv Water Resour 34(1):83-97

Cano-Casas L, Escobar-Martínez JF (2011) Monitoring network design supported by GIS tools and geospatial modeling. Aqua-LAC 3(1):18-25

Cherry JA, Parker BL, Bradbury KR, Eaton TT, Gotkowitz MG, Hart DJ (2004) Role of aquitards in the protection of aquifers from contamination: a "state of the science" report. Research Foundation, Denver, $144 \mathrm{pp}$

CONAGUA (2009) Update the average annual availability of groundwater aquifer 1501, Valley of Toluca, State of Mexico, Internal report. CONAGUA, Toluca, México, p 40

CONAGUA (2012) Database of measurements of groundwater levels in the Toluca Valley Aquifer (1969-2012). México, Internal Report CONAGUA

CONAGUA-Desarrollo y Sistemas, S.A (2005) Areas of drinking water reservoir for the city of Toluca, Internal report. CONAGUA, Toluca, México, p 154

CONAGUA-GTZ (2008) Management plan for the Lerma river watershed in the Toluca Valley Aquifer. Final report. Mexico. http://www2.gtz.de/dokumente/gut/gtz2008-13990es-cuenca-rio-lerma.pdf

Consultores A (1996) Study of hydrodynamic simulation and design of observational networks of aquifers in Calera, San Luis Potosí y Toluca aquifer. Tech Rep 1:235, S.A

Dhar A, Patil RS (2012) Multiobjetive design of groundwater monitoring network under epistemic uncertainty. Water Resour Manag 26:1809-1825

Díaz-Viera M (2008) An alternative methodology to the design of a new network groundwater monitoring with almost no information. Institute of geophysics, UNAM. Mexico. Institute of geophysics and astronomy. CITMA, Cuba, pp 8 
Eastman JR (2012) Guide to GIS and image processing. Clark University, Whistler, Canada

Eliasson A, Rinaldi FM, Linde N (2003) Multicriteria decision aid in supporting decisions related to groundwater protection. Environ Manag 32(5):589-601

Esteller M, Diaz C (2002) The groundwater in a watershed in height: Valley of Toluca. In: Antón D, Díaz-Delgado C (eds) Drought in a world of water. Piriguazú Ediciones y CIRA-UAEM, Toluca, México, pp 101-124

Esteller MV, Rodríguez R, Cardona A (2011) Evaluation of hydrochemical changes due to intensive aquifer exploitation: case studies from Mexico. Environ Monit Assess 184:5725-5741

Expósito JL (2012) Hydrodynamic and hydrochemical characteristics of Toluca Valley multilayer aquifer and its implications for optimizing strategies for the groundwater quality protection. Dissertation, $\mathrm{Ph}$. D. thesis, Universidad Autonoma del Estado de México

Foukh ML (2001) Decision-support system for domestic water demand forecasting and management. Water Resour Manag 15(6):363-382

Garduño VH, Arreygue E, Isdare I, Rodríguez G (2001) Effects of faults associated with overexploitation of aquifers and the presence of potentially seismic faults in Morelia, Michoacán, México [Efectos de las fallas asociadas a sobreexplotación de acuíferos y la presencia de fallas potencialmente sísmicas en Morelia, Michoacán, México]. Rev Mex Cienc Geol 18(1):37-54

Hajkowicz S, Collins K (2007) A review of multiple criteria analysis for water resource planning and management. Water Resour Manag 21(9):1553-1566

Hanich L, Zouhri L, Vachard D, Colbeaux JP, Gorini C (2008) A multicriteria approach for well drilling in productive zones of fissured systems. Hydrol Sci J 53(1):192-203

INEGI (2010) XIII general census of population and housing 2010, State of Mexico. Basic tabulations, Mexico City

Júnez-Ferreira HE, Herrera GS (2013) A geostatistical methodology for the optimal design of space-time hydraulic head monitoring networks and its application to the Valle de Querétaro aquifer. Environ Monit Assess 185(4):3527-3549

Marinoni O (2004) Implementation of the analytical hierarchy process with VBA in ArcGIS. Comput Geosci 30(6):637-646

Martín del Campo MA, Esteller MV, Expósito JL, Hirata R (2014) Impacts of urbanization on groundwater hydrodynamics and hydrochemistry of the Toluca Valley aquifer (Mexico). Environ Monit Assess 184(7): 5725-5741

Mei X, Rosso R, Huang GL, Nie GS (1989) Application of analytical hierarchy process to water resources policy and management in Beijing, China. Closing the gap between theory and practice. In: proceedings of the Baltimore symposium, May. IAHS Publ 180:73-83

Mejía JA (2007) Factors affecting the vulnerability of the aquifer system in Salamanca, Gto. Dissertation Ph. D. thesis, Universidad Nacional Autonoma de México

Mogheir Y, de Lima JLMP, Singh VP (2009) Entropy and multi-objective based approach for groundwater quality monitoring network assessment and redesign. Water Resour Manag 23:1603-1620

Molerio L, Torres J, Rocamora E, Guerra M, Rodríguez K (2002) Optimization of the monitoring network regime of groundwater in the South Basin of Matanzas, Cuba. J Hydraul Eng Environ XXIII(2):10-22

Orozco J, Figueroa G (1991) Chronological description of the development of knowledge on cracking soils. Soil Cracking Mex Soc Soil Mech A.C. 1-11

Osorio JC, Orejuel JP (2008) The analytic hierarchy process (AHP) and multi-criteria decision making. Application example. SciTech XIV(39):247-252

Panagopoulos GP, Bathrello GD, Skilodimou HD, Martsouka FA (2012) Mapping urban water demands using multi-mriteria analysis and GIS. Water Resour Manag 26:1347-1363

Preziosi E, Petrangeli AB, Goiliano G (2013) Tailoring groundwater quality monitoring to vulnerability: a GIS procedure for network design. Environ Monit Assess 185:3759-3781

Rao KHVD (2005) Multi-criteria spatial decision analysis for forecasting urban water requirements: a case study of Dehradun City, India. Landsc Urban Plan 71(2-4):163-174

Reitsma RF (1996) Structure and support of water resources management and decision-making. J Hydrol 177(34):253-268

Saaty TL (1977) A scaling method for priorities in hierarchical structures. J Math Psychol 15:234-281

Saaty TL (1990) How to make a decision: the analytic hierarchy process. Eur J Oper Res 48:2-26

Saaty TL (2006) Rank from comparisons and from ratings in the analytic hierarchy/ network processes. Eur J Oper Res 168:557-570

Salazar R, Stone J, Yakowitz D, Slack D (2005) Multicriteria analysis in an irrigation district in Mexico. J Irrig Drain Eng-ASCE 131(6):514-524

Srdjevic B, Medeiros Y, Srdjevic Z, Schaer M (2002) Evaluating management strategies in Paraguacu river basin by analytic hierarchy process. In: Rizzoli AE, Jakeman AJ (eds) Integrated assessment and decision support, first biennial meeting of the international environmental modelling and software society. iEMSs, Manno, Switzerland, pp 42-47 
Tuinhof A, Foster S, Kemper K (2002) Requirements of groundwater monitoring. GWP associated program, World Bank. EEUU, Washington DC, p 10

Uddameri V, Andruss T (2013) A GIS-based multi-criteria decision-making approach for establishing a regionalscale groundwater monitoring. Environ Earth Sci 71:2617-2628

UNAM (1994) Geological map of the State of Mexico. UNAM, México City

UNESCO (2009) Water in a changing world. The United Nations world water development report 3. http:// publishing.unesco.org

Van Gauwenberg N, Pinte D, Tilmant A, Frances I, Pulido-Bosch A, Vanclooster M (2008) Multi-objective, multiple participant decision support for water management in Andax catchment, Almeria. Environ Geol 54: 479-489

Weng S (2005) A scenario-based multiobjective optimization method for water resources management. Dissertation, University of Regina, Canada, pp 152

Wu Y (2004) Optimal design of a groundwater monitoring network in Daqing, China. Environ Geol 45:527-535

Zhang Y, Pinder GF, Herrera GS (2005) Least cost design of groundwater quality monitoring networks. Water Resour Res 41, W08412. doi:10.1029/2005WR003936 